\title{
EFICÁCIA DE HERBICIDAS GRAMINICIDAS APLICADOS EM PRÉ-EMERGÊNCIA NO SISTEMA DE SEMEADURA DIRETA DO MILHO ${ }^{1}$
}

\author{
VITOR SPADER $^{2}$ e RIBAS A. VIDAL ${ }^{3}$
}

\section{RESUMO}

A produtividade do milho tem sido diminuida pela interferência com plantas daninhas durante o período crítico de prevenção da interferência (PCPI). Foi desenvolvido um experimento na EEA/UFRGS em Eldorado do Sul, RS, na safra de 1998/99, com objetivo de avaliar a eficácia de herbicidas graminicidas, aplicados em pré-emergência, no controle de Brachiaria plantaginea (BRAPL) no sistema de semeadura direta do milho. O híbrido utilizado foi AG 5011 numa população de 70.000 plantas/ha. Os tratamentos foram 5 herbicidas com 2 doses, além de testemunha capinada e testemunha sem controle. Os herbicidas com as respectivas doses $\left(\mathrm{kg}\right.$ i. a. ha $\left.{ }^{-1}\right)$ foram, acetochlor $(3,0$ e 4,0$)$, metolachlor (2,5 e 3,0), trifluralin $(3,0$ e 4,0), pendimethalin $(2,5$ e 3,0$)$ e isoxaflutole $(0,06 \mathrm{e}$ $0,07 \mathrm{~g}$ i. a. $\left.\mathrm{ha}^{-1}\right)$. $\mathrm{O}$ delineamento experimental foi o de blocos casualizados com 4 repetições.
Avaliou-se o nível de controle, população e produção de matéria seca das plantas de BRAPL e rendimento de grãos do milho. A infestação de 117 plantas $/ \mathrm{m}^{2}$ de BRAPL reduziu em $80 \%$ o rendimento de grãos do milho. Quanto maior a produção de matéria seca da BRAPL, durante o PCPI, mais intenso foi seu efeito sobre o rendimento da cultura. Os herbicidas reduziram a infestação e aumentaram o rendimento do milho em relação à testemunha sem controle. Os melhores controles de BRAPL foram obtidos com isoxaflutole e, de modo geral, com a dose mais elevada. O rendimento do milho foi negativamente correlacionado com a população e produção de matéria seca das plantas daninhas, indicando que redução no número de plantas de BRAPL, aumentam o rendimento do milho.

Palavras chave: Planta daninha, controle químico, Brachiaria plantaginea.

\section{ABSTRACT \\ Efficacy of no-till applied graminicide herbicides in corn}

The productivity of corn crop is reduced by the interference of weeds. An experiment was conducted at Eldorado do Sul, RS/Brazil, in 19981999, to evaluate the efficacy of grass herbicides applied during preemergence on the control of Brachiaria plantaginea (BRAPL) in no-tilled corn. The corn hybrid was AG 5011 planted at 70.000 plants/ha. The treatments consisted of five herbicides with its two rates each $\left(\mathrm{kg}\right.$ i. a.ha $\left.{ }^{-1}\right)$, as follows: acetochlor $(3,0$ and 4,0$)$, metolachlor $(2,5$ and 3,0), trifluralin $(3,0$ and 4,0$)$, pendimethalin $(2,5$ and 3,0$)$ and isoxaflutole $(0,06$ and 0,07$)$. The experiment al desing was a complet block with four replicates. It was assessed the weed control, the number of plants, BRAPL dry mass and corn grains yiel. Best weed control was obtained with isoxaflutole and at higher rates, the weed control increased. Corn yield was negatively related to BRAPL density and dry mass indicating that

\footnotetext{
${ }^{1}$ Recebido para publicação em 09/06/99 e na forma revisada em 01/09/99.

${ }^{2}$ Eng $^{\mathrm{o}}$. Agr ${ }^{\circ}$, Estudante do Curso de Mestrado em Fitotecnia na Faculdade de Agronomia da Universidade Federal do Rio Grande do Sul. C.P. 776, CEP: 90.001.970, Porto Alegre/RS. E-mail: spader@ vortex.ufrgs.br.

${ }^{3}$ Eng $^{\circ}$. Agr ${ }^{\circ}, \mathrm{PhD}$, Professor do Departamento de Plantas de Lavoura da Faculdade de Agronomia da Universidade Federal do Rio Grande do Sul. Pesquisa dor do CNPq. C.P. 776, CEP: 90.001.970, Porto Alegre/RS. E-mail: vidal@if1.if.ufrgs.br.
} 
increasing BRAPL plants and mass reduced corn yield.

\section{INTRODUÇÃO}

O milho é bastante cultivado no sistema de semeadura direta, principalmente na rotação com a cultura da soja. Entretanto, a produtividade do milho tem sido prejudicada pela interferência exercida por plantas daninhas que se desenvolvem, principalmente durante o período inicial do estabelecimento da cultura. Este período crítico para prevenção da interferência (PCPI) está compreendido entre 10 e 50 dias após a emergência do milho (Sales, 1991). O rendimento do milho foi afetado pelo aumento da infestação com Abutilon theophrasti durante o PCPI, reduzindo em $30 \%$ com 5 plantas $/ \mathrm{m}^{2}$ e $65 \%$ com 30 plantas $/ \mathrm{m}^{2}$ em relação à testemunha sem infestação (Lindquist \& Mortensen, 1998).

O controle de plantas daninhas em milho no sistema de semeadura direta vem sendo realizado, principalmente com herbicidas aplicados na superfície do solo em préemergência. No sistema de semeadura direta ocorre maior acúmulo de palha na superfície do solo podendo afetar o comportamento de herbicidas aplicados em pré-emergência os quais, são aplicados sobre a palha ficando mais expostos à radiação solar, às altas temperaturas e à adsorção nos resíduos vegatais. Com isso os herbicidas menos sensíveis a volatilização e fotodegradação podem ser mais eficazes no controle das plantas daninhas, nestas condições.

De fato, o aumento da quantidade de resíduos vegetais em cobertura do solo reduziu a quantidade de metolachlor na superfície do solo comparado com o solo sem resíduos (Crutchfield et al. 1985). Além disso, no sistema de semeadura direta, a perturbação do solo é reduzida, desenvolvendo ambiente com maior teor de matéria orgânica e com alta atividade microbiana, principalmente na camada superficial do solo (Dick, 1983; Lal et al. 1994) afetando a atividade de alguns herbicidas. Acetochlor foi mais eficaz do que metolachlor no controle de Brachiaria
Key words: Weed, chemical control, Brachiaria plantaginea.H.

platyphylla, quando aplicados sobre a palha no sistema de semeadura direta e sem chuva durante nove dias após a aplicação, indicando que acetochlor é mais estável nestas condições (Mueller \& Hayes, 1997). Quando ocorreu chuva logo após a aplicação, metolachlor foi mais eficaz do que acetochlor e alachlor. A chuva removeu os herbicidas da palha levando-os até o solo, onde o metolachlor foi dissipado mais lentamente, por ter estrutura química mais estável e maior adsorção aos colóides orgânicos e minerais do solo, resultando em maior persistência e controle das plantas daninhas (Buhler \& Daniel, 1988; Mueller \& Hayes, 1997). Metolachlor foi menos eficáz do que alachlor e pendimethalin no controle de Setaria faberi no sistema de semeadura direta do que no sistema com revolvimento do solo, e pendimethalin proporcionou melhor controle do que metolachlor e alachlor no plantio direto (Buhler \& Daniel, 1988).

Outro fator muito importante para a eficácia dos herbicidas é a dose utilizada. A dose mais eficaz varia para os diferentes herbicidas e plantas daninhas. Pendimethalin na dose de 1.1 $\mathrm{kg}$ de i.a. ha ${ }^{-1}$ controlou Abutilon theophrasti e proporcionou aumento no rendimento do milho em $35 \%$ em relação a testemunha sem controle, entretanto quando a dose de pendimethalin foi reduzida para $0.6 \mathrm{~kg}$ de i.a. ha-1 ${ }^{-1}$ o rendimento do milho foi reduzido em $15 \%$ em relação a testemunha sem infestação (Schemenk \& Kells, 1998), indicando que a dose utilizada tem influência na infestação de plantas daninhas, podendo afetar o rendimento do milho. Metolachlor (2.2 kg de i.a. ha $\left.{ }^{-1}\right)$ aplicado no sistema de semeadura direta, controlou $65 \%$ das gramíneas anuais e reduziu a infestação e a matéria seca das plantas daninhas em $96 \%$ em relação à testemunha sem controle, aos 28 dias após o tratamento - DAT, e $50 \%$ aos 56 DAT (Novosel et al. 1998). Isoxaflutole (158g de i.a. $\mathrm{ha}^{-1}$ ) apresentou residual de aproximadamente seis semanas após o tratamento no sistema de 
semeadura direta, controlando várias plantas daninhas gramíneas (Young \& Hart, 1998). Além disso, verificou-se que isoxaflutole tem atividade e absorção foliar, principalmente, quando misturado com adjuvantes a base de óleo vegetal, podendo ser aplicado antes da semeadura para controlar algumas gramíneas existentes, apresentando efeito residual para controlar as plantas que germinarem no início do ciclo do milho (Young \& Hart, 1998).

Das plantas daninhas infestantes das culturas de verão, a Brachiaria plantaginea é a gramínea de maior incidência na Região Sul do Brasil (Kissmann, 1991). Esta espécie causa forte competição com as culturas anuais, principalmente milho e soja, provocando prejuízos consideráveis ao rendimento e qualidade da produção (Kissmann, 1991; Fleck, 1996). Lorenzi (1991) relata que Brachiaria plantaginea apresenta diferentes graus de suscetibilidade aos herbicidas aplicados em pré-emergência na cultura do do milho. A intensificação do controle químico da Brachiaria plantaginea tem aumentado a pressão de seleção sobre esta espécie, facilitando o surgimento de biótipos resistentes a alguns herbicidas (Vidal et al. 1997).

Os herbicidas aspergidos em préemergência na cultura do milho apresentam comportamento diferenciado no solo e nas plantas de Brachiaria plantaginea, possibilitando o surgimento de plantas daninhas ainda durante o PCPI, dependendo do herbicida e da dose utilizados e das condições do ambiente. Este trabalho teve como objetivo avaliar a eficácia de herbicidas graminicidas aplicados em préemergência, no controle de Brachiaria plantaginea no sistema de semeadura direta do milho.

\section{MATERIAL E MÉTODOS}

O experimento foi conduzido em campo, durante a estação de crescimento 1998/99, em área da Estação Experimental Agronômica da Universidade Federal do Rio Grande do Sul (EEA/UFRGS). O solo da área experimental foi classificado como podzólico vermelho escuro distrófico, com $38 \%$ de argila, $\mathrm{pH}$ em água 5.8, matéria orgânica $2.2 \%, 8 \mathrm{ppm}$ de fósforo, 260 ppm de potássio e $7.5 \mathrm{me} / \mathrm{dl}$ de capacidade de troca de cátions.

O milho, cultivar AG 5011, foi implantado no sistema de semeadura direta, sendo que a cultura de cobertura do solo utilizada foi a aveia preta (Avena strigosa), semeada no mês de junho e dessecada no mês de outubro de 1998, com glifosate (400 g. de e.a. ha $\left.{ }^{-1}\right)$, produzindo 5.6 toneladas de matéia seca. ha ${ }^{-1}$. A adubação foi feita na linha de semeadura com $600 \mathrm{~kg} / \mathrm{ha}$ da fórmula NPK 15-20-20. Realizou-se adubação nitrogenada de cobertura com 100 e $150 \mathrm{~kg}$ de $\mathrm{N}$. ha $^{-1}$ aos 20 e 40 dias após a emergência-DAE, respectivamente. $\mathrm{O}$ delineamento experimental utilizado foi o de blocos casualizados com 4 repetições. Os tratamentos utilizados foram 5 herbicidas com duas doses, testemunha sem controle e testemunha capinada durante todo o ciclo da cultura. Os herbicidas com as respectivas doses (kg i. a. ha $\left.{ }^{-1}\right)$ foram, acetochlor $(3,0$ e 4,0), metolachlor $(2,5$ e 3,0$)$, trifluralin $(3,0$ e 4,0), pendimethalin $(2,5$ e 3,0$)$ e isoxaflutole $(0,06$ e $0,07)$.

O tamanho das parcelas foi de $10 \times 3,2$ metros, contendo 4 fileiras de milho, espaçadas de $0,80 \mathrm{~m}$ e com 5,6 plantas por metro linear na fileira, perfazendo população de 70.000 plantas de milho. ha ${ }^{-1}$ após o desbaste, realizado aos 10 DAE. Os herbicidas foram aplicados imediatamente após a semeadura do milho utilizando pulverizador costal pressurizado com gás carbônico $\left(\mathrm{CO}_{2}\right)$, equipado com barra de 2,0 metros e bicos Teejet 80.03, mantendo-se a pressão constante com 150 $\mathrm{KPa}$, obtendo-se vazão equivalente a 220 litros. $\mathrm{ha}^{-1}$. Para o controle de plantas daninhas de folhas largas foi aplicado atrazina $(2,0 \mathrm{~kg}$ de i.a./ha) em toda a área do experimento, em pré-emergência. Aos 5 dias após os tratamentos (DAT), aplicou-se $20 \mathrm{~mm}$ de chuva via irrigação por aspersão. Durante os períodos em que a precipitação pluvial foi insuficiente para suprir a demanda de água pela cultura, efetuou-se irrigação por aspersão, mantendo a umidade do 
solo adequada para o desenvolvimento das plantas de milho durante todo seu ciclo.

As avaliações foram feitas nas duas linhas centrais descontando-se 1 metro em cada extremidade, perfazendo $12,8 \mathrm{~m}^{2}$ de área útil. Avaliou-se o rendimento de grãos do milho, população e matéria seca das plantas de Brachiaria plantaginea (BRAPL). $\mathrm{m}^{-2}$, a eficácia dos herbicidas no controle da BRAPL através do método quantitativo, caracterizado pela avaliação visual empregando escala percentual, onde a testemunha com capina, mantida sem plantas daninhas durante todo o ciclo do milho, representou $0 \%$ de incidência de plantas daninhas e a testemunha sem capina, $100 \%$. As determinações foram feitas aos 35 e aos 55 dias após a aplicação dos tratamentos (DAT). Os dados foram submetidos à análise de variância pelo teste F. Para verificar diferenças entre os herbicidas aplicou-se o teste de Tukey, e para as doses aplicou-se o teste de DMS, ambos ao nível de significância de $5 \%$ de probabilidade.

\section{RESULTADOS E DISCUSSÃO}

A população de plantas de Brachiaria plantaginea (BRAPL) variou de zero na testemunha capinada até 117 plantas $/ \mathrm{m}^{2}$ na testemunha sem controle, aos 55 dias após os tratamentos (DAT) (Tabela 1). A emergência da BRAPL foi pequena até 20 DAT em todos os tratamentos, exceto nas testemunhas sem herbicida, e aumentou a partir desta data variando nos diferentes tratamentos. Tanto aos 35 como aos 55 DAT, a infestação de BRAPL foi maior nos tratamentos sem aplicação de herbicidas. Nos tratamentos com herbicidas, a infestação foi mais elevada com a menor dose, para todos os herbicidas (Tabela 1), concordando com Schemenk \& Kells (1998), os quais encontraram diferenças na população de plantas daninhas com diferentes doses de herbicida.

Os tratamentos com isoxaflutole foram os mais eficazes e com acetochlor e metolachlor os menos eficazes na redução da população de
BRAPL (Tabela1). Resultados obtidos por Young \& Hart (1998) mostraram elevado controle de gramíneas anuais com isoxaflutole, e Mueller \& Hayes (1997) observaram diferentes níveis de controle de gramíneas anuais com metolachlor, acetochlor e pendimethalin. Aos cinco dias após a aplicação dos herbicidas, aplicou-se $20 \mathrm{~mm}$ de água via irrigação por aspersão. Especula-se que os herbicidas tenham sido removidos da palha de aveia, em cobertura, entrando em contato com o solo, diminuindo as perdas por volatilização e fotodegradação. No solo, especula-se que o isoxaflutole tenha sido mais estável e com menores perdas, permitindo o controle das plantas de BRAPL durante o PCPI. Por outro lado é possível que as perdas ocorridas no solo tenham sido elevadas para metolachlor e acetochlor. Mueller \& Haynes (1997), observaram que acetochlor é menos sensível à volatilização e fotodegradação e foi mais eficaz do que metolachlor no controle de Brachiaria platyphylla no sistema de semeadura direta, sem ocorrência de chuva até 9 dias após a aplicação. Buhler \& Daniel (1988) verificaram que metolachlor apresentou controle das plantas daninhas superior ao acetochlor quando incorporados ao solo. Os mesmos autores observaram que metolachlor apresenta estrutura química mais estável diminuindo sua dissipação no solo.

O melhor nível de controle da BRAPL foi obtido com a dose mais elevada, para todos os herbicidas, tanto aos 35 como aos 55 DAT (Tabela 2). Na menor dose, isoxaflutole e trifluralin mostraram-se superiores, e acetochlor inferior aos demais, no controle de BRAPL. Na maior dose, isoxaflutole não diferiu da testemunha capinada e foi superior aos demais herbicidas, os quais apresentaram comportamento semelhante entre si aos 35 DAT. Aos 55 DAT isoxaflutole foi o mais eficaz nas duas doses, e acetochlor mostrou-se inferior aos demais, na dose mais elevada (Tabela 2). Verifica-se que o nível de controle da BRAPL foi maior aos 35 DAT do que aos 55 DAT, em todos os tratamentos com herbicidas (Tabela 2). 
Eficácia de herbicidas graminicidas aplicados em pré-emergência no sistema de semeadura direta do milho

TABELA 1. População de Brachiaria plantaginea aos 35 e aos 55 dias após o tratamento (DAT) com herbicidas aplicados em pré-emergência em duas doses. EEA/UFRGS, Eldorado do Sul, RS, 1999.

\begin{tabular}{|c|c|c|c|c|c|c|}
\hline \multirow{3}{*}{ Tratamentos } & \multicolumn{6}{|c|}{ População (plantas $/ \mathrm{m}^{2}$ ) } \\
\hline & \multicolumn{3}{|c|}{35 DAT } & \multicolumn{3}{|c|}{55 DAT } \\
\hline & Dose 1 & Dose 2 & Média & Dose 1 & Dose 2 & Média \\
\hline acetochlor & 48 & 27 & $37 \mathrm{~b}$ & 67 & 49 & $58 \mathrm{~b}$ \\
\hline metolachor & 35 & 23 & $29 \mathrm{bc}$ & 55 & 37 & $46 \mathrm{bc}$ \\
\hline isoxaflutole & 16 & 10 & $13 \mathrm{~d}$ & 26 & 15 & $21 \mathrm{~d}$ \\
\hline pendimethalin & 29 & 18 & $23 \mathrm{~cd}$ & 51 & 35 & $43 \mathrm{c}$ \\
\hline trifluralin & 33 & 20 & $26 \mathrm{bc}$ & 51 & 37 & $44 \mathrm{c}$ \\
\hline testunha capinada & 0 & 0 & $0 \mathrm{e}$ & 0 & 0 & $0 \quad \mathrm{e}$ \\
\hline testemunha infestada & 89 & 89 & $89 a$ & 117 & 117 & $117 \mathrm{a}$ \\
\hline Média & $36 \mathrm{~A}$ & $26 \mathrm{~B}$ & & $54 \mathrm{~A}$ & $42 \mathrm{~B}$ & \\
\hline $\mathrm{CV}(\%)$ & \multicolumn{3}{|c|}{24,5} & \multicolumn{3}{|c|}{25,1} \\
\hline
\end{tabular}

Médias, dentro de cada época de avaliação, seguidas pela mesma letra (maiúscula na linha e minúscula na linha) não diferem entre si, $\mathrm{P}>0.05$.

TABELA 2. Controle de Brachiaria plantaginea em milho (escala de 0 à 100) com cinco herbicidas aplicados em pré-emergência e duas doses, em duas épocas de avaliação (dias após o tratamento - DAT) do milho. EEA/UFRGS, Eldorado do Sul, RS, 1999.

\begin{tabular}{|c|c|c|c|c|c|c|c|}
\hline \multirow{3}{*}{ Tratamentos } & \multicolumn{7}{|c|}{$\%$ de controle } \\
\hline & \multicolumn{4}{|c|}{$35 \mathrm{DAT}$} & \multicolumn{3}{|c|}{$55 \mathrm{DAT}$} \\
\hline & \multicolumn{2}{|c|}{ Dose 1} & \multicolumn{2}{|c|}{ Dose 2} & Dose 1 & \multicolumn{2}{|c|}{ Dose 2} \\
\hline acetochlor & 60 & $\mathrm{~B} \mathrm{c}$ & 80 & $\mathrm{Ab}$ & $45 \mathrm{~B} \mathrm{c}$ & 55 & A c \\
\hline metolachor & 70 & $\mathrm{~B} \mathrm{~b} \mathrm{c}$ & 85 & $\mathrm{Ab}$ & $53 \mathrm{~B} \mathrm{c}$ & 65 & $\mathrm{Abc}$ \\
\hline isoxaflutole & 80 & $\mathrm{~B} \mathrm{~b}$ & 96 & $\mathrm{~A} \mathrm{a}$ & $80 \mathrm{~B} \mathrm{~b}$ & 90 & $\mathrm{~A}$ a \\
\hline pendimethalin & 70 & $\mathrm{~B} \mathrm{~b} \mathrm{c}$ & 85 & $\mathrm{Ab}$ & $55 \mathrm{~B} \mathrm{c}$ & 65 & $\mathrm{Abc}$ \\
\hline trifluralin & 75 & $\mathrm{~A} \mathrm{~b}$ & 80 & $\mathrm{Ab}$ & $55 \mathrm{~B} \mathrm{c}$ & 70 & $\mathrm{Ab}$ \\
\hline testunha capinada & 100 & A a & 100 & $\mathrm{~A} \mathrm{a}$ & $100 \mathrm{~A} \mathrm{a}$ & 100 & A a \\
\hline testemunha infestada & 0 & Ad & 0 & Ac & $0 \quad \mathrm{Ad}$ & 0 & $\mathrm{Ad}$ \\
\hline $\mathrm{CV}(\%)$ & \multicolumn{4}{|c|}{4,6} & \multicolumn{3}{|c|}{4,5} \\
\hline
\end{tabular}

Médias, dentro de cada época de avaliação, seguidas pela mesma letra (minúscula nas colunas e maiúscula nas linhas) não diferem entre si, $\mathrm{P}>0.05$.

Especula-se que as perdas para o ambiente e a adsorção aos colóides minerais e orgânicos do solo, tenham se acentuado com o decorrer do tempo após a aplicação, reduzindo o controle da BRAPL, aos 55 DAT, comparado com o controle obtido aos 35 DAT. De acordo com Dick (1983) e Lal et al. (1994), alto teor de matéria orgânica e atividade microbiana elevada afetam a atividade da maioria dos herbicidas no solo.

Os tratamentos com isoxaflutole apresentaram menor produção de matéria seca de BRAPL comparado com os demais herbicidas, os quais mostraram resultados semelhantes entre si (Tabela 3). 
TABELA 3. Matéria seca $\left(\mathrm{g} / \mathrm{m}^{2}\right)$ de Brachiaria plantaginea aos 55 dias após o tratamento com herbicidas aplicados em pré-emergência, e rendimento de grãos de milho (kg.ha $\left.{ }^{-1}\right)$. EEA/UFRGS, Eldorado do Sul, RS, 1999.

\begin{tabular}{|c|c|c|c|c|c|}
\hline \multirow[t]{2}{*}{ Tratamentos } & \multicolumn{3}{|c|}{$\begin{array}{c}\text { Matéria seca de BRAPL } \\
\left(\mathrm{g} / \mathrm{m}^{2}\right)\end{array}$} & \multicolumn{2}{|c|}{$\begin{array}{l}\text { Rendimento de grãos de milho } \\
\left({\left.\mathrm{kg} \cdot \mathrm{ha}^{-1}\right)}\right.\end{array}$} \\
\hline & Dose 1 & Dose 2 & Médias & Dose 1 & Dose 2 \\
\hline Acetochlor & 38 & 29 & $33 \mathrm{~b}$ & $3701 \mathrm{~B} \mathrm{~d}$ & $5059 \mathrm{~A} \mathrm{~d}$ \\
\hline Metolachor & 37 & 22 & $29 \mathrm{~b}$ & $4381 \mathrm{~B} \mathrm{~d}$ & 7014 A c \\
\hline Isoxaflutole & 16 & 10 & $13 \mathrm{c}$ & $8461 \mathrm{~A} \mathrm{~b}$ & $9333 \mathrm{~A} \mathrm{a}$ \\
\hline pendimethalin & 26 & 19 & $22 \mathrm{bc}$ & $6269 \mathrm{~B} \mathrm{c}$ & 7868 A b c \\
\hline trifluralin & 27 & 15 & $21 \mathrm{bc}$ & $5928 \mathrm{~B} \mathrm{c}$ & $8890 \mathrm{~A} \mathrm{a} \mathrm{b}$ \\
\hline testemunha capinada & 0 & 0 & $0 \quad \mathrm{~d}$ & $9995 \mathrm{~A} \mathrm{a}$ & 9995 A a \\
\hline testemunha infestada & 59 & 59 & $59 \mathrm{a}$ & $2015 \mathrm{~A} \mathrm{e}$ & $2015 \mathrm{~A} \mathrm{e}$ \\
\hline Médias & $25 \mathrm{~A}$ & $18 \mathrm{~B}$ & & & \\
\hline $\mathrm{CV}(\%)$ & \multicolumn{2}{|c|}{17} & & & 14,1 \\
\hline
\end{tabular}

Médias, seguidas pela mesma letra (maiúscula nas linhas e minúscula nas colunas) não diferem entre si, P > 0.05.

Todos os tratamentos com herbicidas aumentaram o rendimento do milho comparados com a testemunha sem controle de BRAPL (Tabela 3). O rendimento foi de $9995 \mathrm{~kg} / \mathrm{ha}$ na testemunha capinada, mostrando que não houve limitações significativas dos fatores do ambiente sobre o potencial de produtividade do híbrido, enquanto que, o rendimento obtido na testemunha sem controle foi de $2015 \mathrm{~kg} \cdot \mathrm{ha}^{-1}$, mostrando que BRAPL exerceu forte competição com o milho pelos recursos do ambiente, diminuindo em $79 \%$ o rendimentode grãos da cultura. De acordo com Lorenzi (1991) e Fleck (1996), a Brachiaria plantagínea apresenta elevado potencial de competição com culturas anuais como milho e soja.

Observa-se que os tratamentos com isoxaflutole, os quais foram os mais eficazes na redução da produção de matéria seca de BRAPL, apresentaram rendimento do milho igual ao tratamento testemunha capinada (Tabela 3). Por outro lado, os tratamentos com acetochlor e metolachlor, que mostraram maior produção de matéria seca da plantas de BRAPL, apresentaram o menor rendimento de grãos do milho (Tabela 3). Nos tratamentos com pendimethalin, trifluralin e isoxaflutole a produção de matéria seca de Brachiaria plantaginea foi semelhante, contudo, o rendimento do milho foi inferior no tratamento com pendimethalin na dose 2 (Tabela 3 ). Especula-se que o pendimethalin pode ter causado injúria nas plantas de milho, reduzindo seu rendimento.

O método de avaliação visual do controle das plantas daninhas, baseado na cobertura do solo pelas plantas, mostrou boa correlação $\left(\mathrm{r}^{2}=\right.$ $0,98)$ com o método de avaliação pela contagem de plantas pois em ambos os métodos observou-se comportamento semelhante no efeito dos herbicidas sobre as plantas de Brachiaria plantaginea (Tabela 1 e 2). O rendimento do milho apresentou alta correlação $\left(r^{2}=0,93\right)$ com a produção de matéria seca, indicando que variações relativamente baixas no número de plantas de BRAPL podem ter efeito significativo no rendimento de grãos da cultura, principalmente quando predominam plantas grandes. Observou-se que quanto maior a produção de matéria seca das plantas de BRAPL durante o PCPI, maior sua capacidade de competição pelos recursos do ambiente e mais intenso é o seu efeito sobre o rendimento da cultura. 


\section{LITERATURA CITADA}

ALMEIDA, F. S., OLIVEIRA, V. F. Controle de ervas daninhas na cultura do milho, Inf. Agropec., , n. 164, p. 81-87, 1980.

BLANCO, H.G., ARAUJO, J. B. M., OLIVEIRA, D. A. Estudo sobre a competição das plantas daninhas na cultura do milho (Zea mays). IV - Determinações do período crítico de competição. Arq. Inst. Biol., São Paulo, v. 43, n. 4, p. 281-297, 1976.

BUHLER, D. .D., DANIEL, T. C. Influence of tillage systems on giant foxtail, Setaria faberi, and velvetleaf, Abutilon theophrasti, density and control in corn, Zea mays. Weed Sci., v. 36, n. , p. 642-647, 1988.

CRUTCHFIELD, D. A., WICKS, G. A., BURNSIDE, C. Effects of winter wheat (Triticum aestivum) straw mulch level on weed control. Weed Sci., v. 33, n. 1, p. 110-114, 1985.

DICK, W. A. Organic carbon, nitrogen and phosphorus concentrations and $\mathrm{pH}$ in soil profiles as affected by tillage intensity. Soil Sci. Soc. Am. J., v. 47, p. 102-107, 1983.

FLECK, N. G. Interferência de papuã (Brachiaria plantaginea) com soja e ganho de produtividade obtido através do seu controle. Pes. Agropecu. Gaúcha, Porto Alegre, v. 2, n. 1, p. 63-68, 1996.

KISSMANN, K. G. Plantas Infestantes e Nocivas. 1. Ed. São Paulo: Basf, 1991. 606 p. p. 67-94.

LAL, R., MAHBOUBI, A. A., FAUSEY, N. R. Long term tillage and rotation effects on properties a central Ohio soil. Soil Sci. Soc. Am. J., v. 58, p. 517-522, 1994.
LINDQUIST, J. L., MORTENSEN, D. A. Tolerance and velvetleaf (Abutilon theophrasti) suppressive ability of two old and two modern corn (Zea mays) hybrids. Weed Sci., v. 46, n. , p. 569-574, 1998.

LOCKE, M. A., BRYSON, C. T. Herbicide-soil interactions in reduced tillage and plant residue management systems. Weed Sci., v. 45, n. , p. 307-320, 1997.

LORENZI, H. Plantas Daninhas do Brasil: terrestres, aquáticas, parasitas, tóxicas e medicinais. 2. ed., Nova Odessa, Editora Plantarum, 1991, $440 \mathrm{p}$.

MILLS, M. S., THURMAN, E. M. Reduction of nonpoint-source contamination of surface and groundwater by starch encapsulated atrazine. Environment Science Technology, v. 28, n. 1, p. 73-79, 1994.

MUELLER, T. C., HAYES, R. M. Effect of tillage and soil-applied herbicides on broadleaf signalgrass (Brachiaria platyphylla) control in corn (Zea mays). Weed Technol., v. 11, n. , p. 698-703, 1997.

NOVOSEL, K. M., RENNER, K. A., KELLS, J. J. et al. Metolachlor efficacy as influenced by three acetolactate synthase-inhibiting herbicides. Weed Technol., v. 12, n. 2, p. 248-253, 1998.

SALES, J. L. Determinação dos períodos de interferência e integração de práticas culturais com herbicidas no controle de plantas daninhas na cultura do milho (Zea mays L.). Piracicaba - SP. 151 p. Tese (Doutorado em Fitotecnia) - Curso de Pósgraduação em Agronomia, ESALQ - USP, 1991.

SCHEMENK, R., KELLS, J. J., Effect of soilapplied atrazine and pendimethalin on velvetleaf (Abutilon theophrasti) 
competitiveness in corn. Weed Technol., v. 12, n. 1, p. 47-52, 1998.

SILVA, J. B. da., CRUZ, J. C., SILVA, A. F. da. Controle de plantas daninhas. Sete Lagoas, MG, 1987. In: EMPRESA BRASILEIRA DE PESQUISA AGROPECUÁRIA, 1987. Sete Lagoas, MG. Recomendações técnicas para a cultura do milho. 3. ed. 1987. p. 31-41 (EMBRAPA - CNPMS. Circular técnica, $4)$.
VIDAL, R. A., FLECK, N. G., OLIVEIRA, N. A., et al. Increasing the number of mechanisms of action of herbicides for management of weed resistence, Brighton, UK, 1997. In: The 1997 Brighton Crop Protection Council, 1997, v. 1, 1202 p. p.363.

YOUNG, B. G., HART, S. E. Optimizing foliar activity of isoxaflutole on giant foxtail (Setaria faberi) with various adjuvants. Weed Sci., v. 46, n. , p. 397-402, 1998. 